\title{
Justicia del Señor en el horizonte de su misericordia
}

\author{
Andrés Ferrada \\ FACULTAD DE TEOLOGÍA \\ PONTIFICIA UNIVERSIDAD CATÓLICA DE CHILE \\ aferradm@uc.cl
}

Resumen: El castigo divino es uno de los temas centrales del Libro de los Números, en especial de Nm 10,11-36,13 que describe la marcha de 40 años del pueblo por el desierto. La punición se muestra como la intervención judicial del Señor que sentencia castigos según criterios de justicia: básicamente los sancionados merecen el castigo en razón de sus culpas. Este enfoque pareciera no condecirse con la bondad y misericordia que resplandecen en la autorevelación del Señor en el Pentateuco (principalmente en Ex 20,5-6 y 34,6a-7). A través del estudio de la sentencia divina de Nm 14,11-35, que condena a la generación del Sinaí a morir en el desierto sin entrar en la tierra prometida, se intenta mostrar que la justicia y la misericordia se corresponden y, por lo mismo, que decretar justicia implica un modo de hacer misericordia.

Palabras clave: Libro de los Números, justicia, misericordia, culpa, castigo, pena de muerte, peregrinación por el desierto.

Abstract: Divine punishment is one of the central themes of the Book of Numbers, especially in Nm 10:11-36:13, where is described the 40 years wandering of the people through the wilderness. The penalty is shown as the judicial intervention of the Lord, who sentences according to criteria of justice: basically the sanctioned deserve punishment because of their guilt. This approach seems not tackled under the goodness and mercy as they shine in the self-revelation of God in the Pentateuch (mainly Ex-34:6a-7; 20: 5-6). Through the study of divine judgment of Nm 14:11-35, which condemns Sinai generation to die in the desert without entering in the Promised Land, we intend to show that justice and mercy are corresponding and, therefore to decree justice implies a way of showing mercy.

Key words: Book of Numbers, justice, mercy, guilt, punishment, death penalty, wandering in the wilderness 


\section{INTRODUCCIÓN}

El pueblo de la alianza debe peregrinar cuarenta años por el desierto debido a su desobediencia al Señor. Este es uno de los contenidos esenciales que trasmite el Libro de los Números ${ }^{1}$. En efecto, Israel debe vagar ese largo tiempo a causa de su rebeldía, que ha merecido tal punición divina. El Señor lo expresa sin ambages en la larga sentencia que pronuncia, en diálogo con Moisés, ante la constatación del grave delito de los israelitas: ellos han murmurado contra el Señor y así lo han despreciado (cf. Nm 14,11-35, particularmente en los vv. 32-35).

¿Cuáles son los criterios en que se funda el castigo divino? ¿Ira o justicia? ¿Venganza o misericordia? Solo el estudio detenido de la sentencia antes mencionada permitirá dilucidar estas interrogantes. Se realizará del siguiente modo: primero un análisis contextual del veredicto; luego, se harán algunas consideraciones diacrónicas; después, se abordarán las principales líneas teológicas contenidas en él; y, finalmente, se reflexionará sobre los criterios en que se sustenta.

\section{Contexto literario de la Sentencia divina de NM I4,Ii-35}

a) El castigo divino en el Libro de los Números

El castigo divino es un tema recurrente en el Libro de los Números. En efecto, en él se narra que Dios castiga sucesivas rebeliones ${ }^{2}$ : comenzando en Taberá con los lamentos del pueblo por la carencia de carne, a los que

1 Para un detallado status quaestionis del estudio de Nm 13-14 y del Libro de los Números en general resulta muy últil su explicación razonada en M. Olickal, $R e-$ bellion in the Wilderness and Rejaection of the Land. An Exegetical Study of Numbers 13-14 (Jerusalem: SBF, 2012), 8-47. Pasa revista a las distintas corrientes y aproximaciones al pasaje con la consideración bastante nutrida de los principales autores y obras.

2 Seguimos la interpretación general del libro de J.-L. SKA, «Estructura del libro de los Números», en Introducción a la lectura del Pentateuco. Claves para la interpretación de los cinco primeros libros de la Biblia, Íbid. (Estella: Verbo Divino, 2001), 59-63. Cf. otras propuestas complementarias como, por ejemplo, D.T. Olson, Numbers. Interpretation. A Bible Commentary for Teaching and Preaching (Louisville: John Knox Press, 1996), 1-8 ó F. VAro, Números (Bilbao: Desclée de Brouwer, 2008), 113. Este último califica a $\mathrm{Nm} \mathrm{13-14}$ como comienzo de las murmuraciones de todo el pueblo después de rebeliones propuestas por grupos marginales $(\mathrm{Nm} 11)$ y de los cercanos a Moisés (Nm 12). 
Dios responde con el envío de miles de codornices, pero también con la plaga subsiguiente en la que murieron "una muchedumbre de glotones" (Nm 11,33-34). Luego las quejas de María y de Aarón, arrogándose la profecía en desmedro de Moisés, que enardecen la ira del Señor, quien envía la lepra sobre aquella mujer ( $\mathrm{Nm}$ 12,1-16). Después, la rebelión del pueblo, azuzada por los nefastos reportes de los espías, que termina con el castigo de la generación del Sinaí (Nm 13-14), cuya resolución es objeto de la presente reflexión. Sigue la violación del sábado por un hombre, quien es condenado a muerte ( $\mathrm{Nm} \mathrm{15,32-36).} \mathrm{Posteriormente,}$ la insurrección de Coré, Datán, Abirón y los rubenitas, más doscientos cincuenta hombres principales, quienes se abrogaban la dignidad sacerdotal contra Moisés y Aarón; Dios interviene y hace que la tierra se los trague (Nm 16,1-35). Más adelante, las quejas del pueblo sediento en Cades, con la reacción del Señor que hace brotar agua de la roca por la intervención de Moisés y el castigo divino contra él y su hermano Aarón por haber desconfiado de Dios en ese trance (Nm 20,1-13). También, las murmuraciones de los israelitas contra Dios, mientras van de camino por el desierto, y el envío de serpientes abrasadoras como punición (Nm 21,4-9). Finalmente, los israelitas en Peor se adhieren al culto a Baal arrastrados por las mujeres moabitas con quienes fornican: Dios los castiga con una plaga ( $\mathrm{Nm} \mathrm{25)}$.

Es claro, hay casos de rebeliones comunitarias y rebeldías personales o de grupos determinados, pero todas terminan con la punición divina, aunque en muchas de ellas se observa también que se abren posibilidades de perdón.

La contrapartida ante esta desoladora experiencia de Israel es su fidelidad al Señor. En efecto, en la medida en que el pueblo sigue la voluntad divina, derrota a sus enemigos y conquista su tierra, tomando posesión de ella: Jormá (Nm 21,1-3); derrota a Sijón y conquista la tierra de los amorreos (Nm 21,21-31); acaba con Og, rey de Basán, y se apodera de su país (Nm 21,32-22,1); guerrea contra Madián y lo vence (Nm 25,16-18; 31,1-12).

En síntesis, es el panorama en el que se enmarca gran parte del Libro

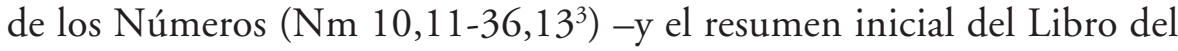

3 Para la estructura del libro seguimos a Knierim en la presentación que hace SKA, Introducción, 59-63. Otras estructuraciones complementarias: Olson, Numbers, 3-7 plantea una estructura bipartita en base a los dos censos contenidos en el libro: 
Deuteronomio (Dt 1,1-4,43) - que relatan los cuarenta años de peregrinación del pueblo por el desierto. La línea gruesa del mensaje es diáfana: en buena medida se narra una seguidilla de castigos por las rebeliones de los israelitas contra la voluntad divina, jalonada de sus victorias en la Transjordania cuando siguen los designios del Señor; estas últimas incluso se pueden considerar el inicio de la conquista de la tierra prometida ${ }^{4}$.

\section{b) La sentencia divina de $\mathrm{Nm}$ 14,11-35}

La sentencia divina de $\mathrm{Nm}$ 14,11-35 pertenece al relato de la exploración de la tierra prometida y sus consecuencias que abarca los capítulos 13 y 14 del Libro de los Números. En la narración, los israelitas dan crédito al tinte aterrador que va tomando el relato de la mayoría de los exploradores enviados a la tierra prometida. Ellos la denuestan advirtiendo sobre la peligrosidad de sus habitantes, pese al cariz contrario de

$\mathrm{Nm}$ 1, que reporta la generación del éxodo y de la alianza del Sinaí, la misma que será punida por su desprecio del Señor; y $\mathrm{Nm}$ 26, que da cuenta de la generación siguiente, los que entrarán en la tierra prometida. Nm 13-14, siempre según Olson, conecta ambos censos. En efecto, en 14,29 se afirma que morirán "todos los registrados en el censo, de todos los que tienen más de veinte años"; refiere al primer censo explícitamente y se usa la expresión "los que tienen más de veinte años", la cual se utiliza repetidas veces en $\mathrm{Nm}$ 1: vv. 1.18.20.22.24.26... La conexión de $\mathrm{Nm} 13-14$ y el segundo censo es aún más explícita porque en la conclusión de este se alude directamente a $\mathrm{Nm}$ 14,6.29-30 (y, además, se vincula expresamente con el primer censo): "Estas son las personas registradas por Moisés y el sacerdote Eleazar, cuando hicieron el censo de los israelitas en las estepas de Moab, junto al Jordán, a la altura de Jericó. Entre estos no figuró ninguno de los que Moisés y el sacerdote Aarón habían registrado en el desierto del Sinaí. Porque el Señor había dicho acerca de ellos: «Morirán en el desierto». Ninguno de ellos sobrevivió, excepto Caleb, hijo de Iefuné, y Josué, hijo de Nun" (Nm 26,63-65). Cf. también en Olson, Numbers, 86-87.

4 SKa, Introducción, 61-62 afirma que "por primera vez el texto dice que Israel «ha conquistado un territorio" y que se "ha establecido". Estos verbos aparecen en $\mathrm{Nm}$

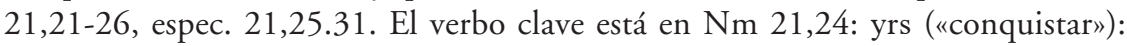
«Israel lo venció [a Sijón] a filo de espada y conquistó su territorio (wayyiras) desde el Arnón hasta el Yaboc...». A partir de este momento, la narración está orientada hacia la conquista. Así, Nm 32 contiene las instrucciones para el reparto de los territorios de Transjordania y Nm 34 los de Cisjordanía. Nm 21,10-20 hace de transición entre estas dos etapas de la marcha por el desierto. Y los oráculos de Balaán (Nm 22-24) ocupan un puesto clave en esta estructura, al inicio de la conquista. En estos capítulos queda demostrado de diversos modos que nadie podrá oponerse al plan divino" [se ha sintetizado levemente la cita]. 
Caleb y Josué que, al contrario, instan a los israelitas a ingresar al país, arguyendo que el Señor está con su pueblo (cf. Nm 13,25-14,9).

La rebelión supone que Dios en el Sinaí había ordenado al pueblo la inmediata entrada y toma de posesión de la tierra prometida. Esta orden, sin embargo, solo es explícita en el texto paralelo de Dt 1,6-8:

El Señor, nuestro Dios, nos habló así en el Horeb: «Ya han estado bastante tiempo en esta montaña. ¡En marcha!, partan y entren en la montaña de los amorreos, y donde todos sus vecinos de la Arabá, la montaña, la tierra baja, el Négueb y la costa del mar; en la tierra de Canaán y el Líbano, hasta el río grande, el río Éufrates. Miren: Yo he puesto esa tierra ante ustedes; vayan a tomar posesión de la tierra que Yahveh juró dar a sus padres Abraham, Isaac y Jacob, y a su descendencia después de ellos».

El Señor reitera la orden poco después en Cades Barnea, luego de que el pueblo hizo el primer trecho del camino desde el Horeb (cf. Dt 1,21). Esta comprensión no pertenece solo al resumen inicial, sino también al cuerpo del relato del Deuteronomio, pues se vuelve a hacer alusión a este mandato más adelante en Dt 9,22-23.

En el Libro de los Números se narra el movimiento de Israel de otro modo ${ }^{5}$. En Nm 10,11-36 encontramos el ofrecimiento que hace Moisés a su cuñado Jobab para que acompañe al pueblo, de modo que lo guíe por el desierto: "nosotros partimos para el lugar del que ha dicho el Señor: se los daré" (Nm 10,29). Es claro, en esta tradición Moisés y el pueblo entienden que la llegada a la tierra prometida requerirá de un camino por el desierto relativamente prolongado. La orden del Señor, trasmitida a Moisés, al menos no es explícita; solo con un cierto esfuerzo se la puede armonizar con la petición que hace Moisés a su cuñado de prestar el servicio de guía. En efecto, inmediatamente se relatan las tres primeras jornadas por el desierto (cf. Nm 10,33-36) y, luego, algunos episodios de quejas contra el Señor y contra Moisés (Nm 11,1-12,16). Todo ello en un recorrido en dos etapas: De Quibrot Hatavá a Jaserot (cf. Nm 11,35) y desde ese lugar al desierto de Parán (cf. Nm 12,16). Se debe notar que en la descripción no se indica ninguna orden divina en relación al desplazamiento de Israel.

5 VARO, Números, 113 hace referencias precisas respecto a las variantes del texto en el Pentateuco Samaritano, varios manuscritos griegos minúsculos y la Hexapla siríaca en los cuales se añade al inicio de $\mathrm{Nm} 13$ un texto muy cercano a Dt 1,20-23, mostrando un intento de armonizar las diferencias entre los relatos de Nm y Dt. 
En Nm 13,1-2, sin embargo, se narra la orden dada por el Señor a Moisés, para que envíe exploradores a la tierra prometida. Debía consistir en una comitiva de doce hombres principales, uno por cada tribu. Así, Moisés envió la comitiva para que informara sobre el don que el Señor estaba por darles (cf. Nm 13,3.17-20). Esta orden divina no se contiene en el relato paralelo del Deuteronomio. Es más, en aquella narración Moisés concede la petición de los israelitas y aprueba el envío de espías sin mediar orden divina alguna (cf. Dt 1,22-23) ${ }^{6}$.

El relato inicial de la exploración deja la impresión de que los espías harán un reporte muy positivo de la tierra que el pueblo de Israel tiene

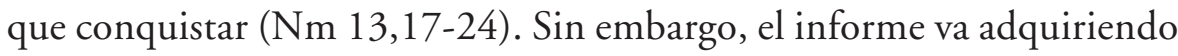
matices espeluznantes y desalentadores en razón del poderío de los habitantes del país y la fortificación de sus ciudades (cf. Nm 13,27-29.3133). Enseguida, los exploradores recomiendan no subir a aquella tierra.

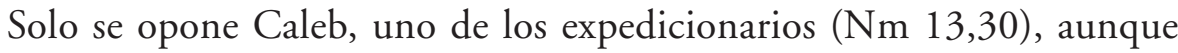
más adelante, se sabrá que también Josué se opuso junto con Caleb $(\mathrm{Nm}$ 14,6-9). Sorprendentemente, con todo, en la sentencia divina que sigue a esta nota aclaratoria, se ignora la oposición de este segundo expía. En efecto, se dirá que solo Caleb será eximido de la pena de muerte $(\mathrm{Nm}$ $14,24)$ y, precisamente, por haber obedecido puntualmente lo que había ordenado el Señor. Con todo, Josué reaparecerá más adelante en la narración, junto a Caleb, entre los liberados de la pena capital en el desierto (Nm 14,30).

La omisión inicial de la reacción de Josué junto a la de Caleb a la negativa postura de los espías $(\mathrm{Nm} 13,30)$ y también su ausencia en $\mathrm{Nm}$ 14,24, no se resuelven con la mera lectura sincrónica. En efecto, si Nm 13 y 14 se tratara de un escrito unificado resultarían contradictorias y hasta altamente absurdas algunas cuestiones que se podrían desprender del texto, tal como lo leemos en su forma actual.

Por ejemplo, cabría plantearse las siguientes preguntas:

- ¿Por qué el narrador olvidó a Josué cuando describió que Caleb, contrarrestando los nefastos reportes de los otros espías, animaba al pueblo a subir a la tierra prometida? (cf. Nm 14,30). Se hubiera esperado

6 La aprobación por parte de Moisés de la propuesta de expedición al país, a iniciativa de los israelitas, será también la razón por qué se le privará de entrar en la tierra prometida (cf. Dt 1,37; 3,26; 34,4). 
que de alguna manera incluyera también a Josué en esa reacción, así como lo hace poco después, cuando narra que Caleb y Josué rasgaron sus vestiduras en señal de oposición a la murmuración del pueblo, precisamente suscitada por esos reportes (cf. Nm 13,30 y Nm $14,6-9)$.

- ¿Sucede que el Señor corrigió su mala memoria -su desvarío- en la larga sentencia que pronuncia contra los culpables, pues en un primer momento solo eximió a Caleb del castigo en razón de su fidelidad, pero luego junto a él también excluyó a Josué? (cf. Nm 14,24 y $14,30)^{7}$.

\section{CONSIDERACIONES DIACRÓNICAS: UN CORO POLIFÓNICO DEL PERDÓN}

Las interrogantes recién planteadas ameritan, ciertamente, una solución desde el punto de vista diacrónico. En efecto, encuentran respuestas satisfactorias solo si se comprende que la sentencia divina de $\mathrm{Nm}$ 14,1135, que sanciona la rebelión de Israel en Cades en el desierto de Parán (cf. $\mathrm{Nm} \mathrm{13,25),} \mathrm{es} \mathrm{la} \mathrm{fusión} \mathrm{de} \mathrm{elementos} \mathrm{de} \mathrm{distintos} \mathrm{origen.} \mathrm{Esto} \mathrm{es,}$ si se la entiende no como una sola voz, sino como una suerte de coro polifónico. Por eso, a continuación se auscultarán las distintas voces que componen el coro polifónico que ofrece el relato actual, permitiendo también observar el aporte de cada una. Las operaciones que se ejecutarán serán básicamente tres: una breve comparación intrabíblica, el recurso a los lugares paralelos, como primera aproximación; luego el estudio de las tensiones internas en el discurso de $\mathrm{Nm}$ 14,11-35 para individuar las distintas voces que lo componen; finalmente, el contraste de ellas con textos relacionados para percibir algunas notas teológicas con que contribuyen a formar el coro actual.

7 Algunos intérpretes recientes se esfuerzan en señalar que o no hay contradicciones ni duplicados, o si los hay no son significativos para la lectura del relato en su forma actual, de modo que no prestan mayor atención a la diacronía del texto. Olickal, Rebellion, 34-40 señala los estudios de Gordon J. Wenham (1981, 1997), Jacob Milgrom (1990), Timothy R. Ashley (1993), David Olson (1996) y David Volgger (2010); a los cuales se pueden sumar otros que, aunque dan mayor cabida a la investigación histórico-crítica, la combinan significativamente con el análisis sincrónico: Jules de Vaulx (1972) y Michael Widmer (2004). En este mismo sentido debe considerarse el completo estudio de B.A. Levine, Numbers 1-20. A New Translation with Introduction and Commentary (Doubleday: The Anchor Yale Bible, 1993), 345-381, especialmente 347-349. 
a) Breve comparación con los paralelos contenidos en Dt 1,19-46

En Dt 1,19-46 se contienen algunas tradiciones escritas paralelas a las que aparecen en Nm 13-14. En Dt 1,34-37 ${ }^{8}$ llama la atención que se nombre solo a Caleb entre los exceptuados de la pena capital, decretada a causa de la incredulidad del pueblo, precisamente por la misma razón que se arguye en $\mathrm{Nm} \mathrm{14,24:} \mathrm{"porque} \mathrm{me} \mathrm{siguió} \mathrm{cabalmente"} \mathrm{(expresión}$ correspondiente exactamente a la de Dt 1,36). Sin embargo, en $\mathrm{Nm}$ 14,24 no se dice explícitamente que Caleb se haya opuesto al pavoroso relato de los espías que instaban al pueblo a no subir inmediatamente a la tierra prometida, como era el querer del Señor. Esto último se expresa en $\mathrm{Nm}$ 13,30. Esa oposición también aparece en el libro del Deuteronomio en Dt 1,29-32, pero está en boca de Moisés, aunque de modo más extenso y explícitamente poniendo como fundamento de la oposición la confianza en el Señor. Esta conexión, si bien se supone, no aparece en $\mathrm{Nm}$ 13,30. Otro punto a considerar en este parangón radica en que en Dt 1,38, el Señor incluye a Josué entre los que entrarán en la tierra prometida, pero no lo hace en razón de una participación análoga a la de Caleb en la oposición a la rebeldía del pueblo, como se describe en Nm 14,6-9. En Dt 1,38 se limita a la aseveración de que será Josué, el "ayudante" de Moisés, quien conducirá la entrada del pueblo en la tierra prometida, en contraste con su "jefe" excluido por decisión divina a causa de su debilidad, pues cedió ante la petición de los israelitas de primero explorar la tierra antes de subir a conquistarla (cf. Dt 1,22.37).

Aunque habría todavía más elementos a considerar, de esta comparación se desprende que muy probablemente en Nm 13-14 se reelaboran las mismas tradiciones escritas que se reportan en Dt 1,19-46 sobre el suceso en cuestión. Sendos textos lo hacen de un modo diferente. Cabe señalar que en la disposición del libro del Deuteronomio hay un elemento ausente: la intercesión de Moisés en favor del pueblo. Es precisamente en esa argumentación donde se pone al descubierto con mayor claridad la razón del perdón divino.

8 Cf. el estudio comparativo contenido de H.J. Curzer, «Spies and Lies: Faithful, Courageous Israelites and Truthful Spies», JSOT 35 n. 2 (2010). También cf. la breve comparación sinóptica en V. SÉneCHAL, «Quel horizon d'écriture pour $\mathrm{Nb}$ 14,11-25», en The Books of Leviticus and Number, ed. Por TH. Römer (Leuven: Uitgeverij Peeters, 2008), 610-612. 
b) Tensiones al interior de la sentencia divina de Nm 14,11-35

En la sentencia de Nm 14,11-35, el Señor comunica a Moisés que acabará con el pueblo que lo ha desdeñado y ha desconfiado de él (v.11) y que hará del mismo Moisés un nuevo pueblo elegido (v.12). Moisés intercede por los israelitas, logrando aplacar al Señor con sus argumentos (vv.14-19), quien perdona al pueblo pero sentencia que los culpables no verán la tierra prometida: es decir, morirán antes de que el pueblo acceda al país (vv.20-24). Establece una excepción: solo Caleb y su clan tomarán posesión de la tierra (cf. v. 24) en atención al espíritu que lo movió y a que lo siguió cabalmente (= obediencia). Es evidente que esta excepción contrasta con la primera decisión divina: ¿por qué solo se tiene en cuenta a Caleb y a su clan una vez que se ha perdonado al pueblo? ¿Consiste el perdón del Señor en la preservación de los inocentes representados en Caleb y su progenie?

La narración continúa y se impone otra contradicción. En los vv.2627 el Señor profiere preguntas retóricas que en cierta medida son paralelas y retoman interrogantes similares planteadas en el v.11. En todos estos versículos se contienen preguntas que se autoplantea el Señor como reacción ante el desdén y la desconfianza del pueblo frente a los espeluznantes reportes de los exploradores (v.11) y a la murmuración consecuente de los israelitas (vv.26-27). El v.27 puede ser leído como una vuelta atrás. Un detalle relevante al comparar estos versículos radica en que en el v.11 el interlocutor del Señor es solo Moisés, mientras que en el v.26, se agrega también a Aarón. Acto seguido, se repite la misma punición, "no entrarán en la tierra" los israelitas que han murmurado contra el Señor (v.30), aunque se agregan especificaciones tanto de la pena como de las personas a las que se les aplica. Respecto de la sanción se aclara que consiste en la pena capital: los culpables morirán en el desierto ("caerán", "sus cadáveres caerán"; "no quedará ninguno en el desierto: todos deben morir", cf. vv.29.32-33.35). Con todo, se amplía el número de los eximidos de esta pena: además de Caleb (y su descendencia, se supone; cf. v.24), se exceptúa a Josué, hijo de Nun (v.30), y a todos los pequeñuelos, esto es, todos aquellos por cuya eventual perdición los israelitas había murmurado (cf. v.3 y v.31). Ciertamente, se refiere a los menores de veinte años, quienes no son considerados sujetos de responsabilidad penal (cf. v.29). Estos, sin embargo, "cargarán con la infidelidad" de sus padres siendo nómades por el desierto hasta que 
toda la generación del Sinaí, salvo los exceptuados, caigan por el camino (v.33). Cuarenta años trashumando, un año por cada día de exploración del país, con la finalidad de que los culpables comprendan qué significa la rebelión contra el Señor (v.34).

c) Delimitación de los componentes de la sentencia divina

El lector atento queda algo desconcertado por esta tercera clarificación de la pena que el Señor quiere infligir al pueblo rebelde, la cual se especifica mucho más como hemos observado, poniendo alguna tensión respecto de las descripciones anteriores. Para considerar todas ellas como provenientes de una sola mano se deben hacer complementos que no están en el texto como, por ejemplo, que al perdón otorgado por el Señor al pueblo gracias a la intercesión de Moisés (cf. v.20) sucede un nuevo plan punitivo, algo distinto al original (vv.21-24; cf. v.12). Decisión que luego tiene un nuevo ajuste (vv.29-35). Solo la consideración de que la sentencia divina es fruto de la fusión coordinada de elementos de distinto origen permite despejar satisfactoriamente estas contradicciones y explicar la forma actual del texto. En ella distinguimos?:

i. Condena divina e intercesión de Moisés con su inmediata acogida por parte del Señor (Nm 14,11b-23a)

No pocos estudios ${ }^{10}$ reconocen que la condena divina e intercesión de Moisés y su inmediata acogida por parte del Señor en Nm 14,11b-23a

9 Se corresponde bastante con el ya clásico estudio de K. SAKenfeld, «The Problem of Divine Forgiveness in Numbers 14», CBQ 37 n. ${ }^{\circ} 3$ (1975): especialmente en 320 distingue: a) Antigua tradición épica (Nm 14,1b.4.11a.23b-25), que asigna a JE según la división de fuentes de la Hipótesis Documental Clásica; b) Intercesión de Moisés (Nm 14,11b-23a), que correspondería a una tradición pre-P, que fue incorporada como suplemento en la antigua tradición épica; c) Edición final perteneciente a un autor o editor $\mathrm{P}$ que da un marco más amplio a las tradiciones más antiguas.

10 Esta delimitación es sostenida por varios importantes exégetas del período final de la hegemonía de la Hipótesis Documental Clásica: M. Noтн, Das vierte Buch Mose: Numeri (Göttingen: Vandenhoeck \& Ruprecht, 1966), 117; G.W. CoATs, Rebellion on the Wilderness: The Murmuring Motif in the Wilderness Traditions of the Old Testament (Nashville: Abingdon Press, 1968), 138-140; S.E. McEvenue, The Narrative Style of the Priestly Writer (Rome: Biblical Institute Press, 1971), 97. También, en los estudios más recientes de O. Artus, Études sur livre des Nombres. Récit, Histoire et Loi Nb 13,1-20,13 (Fribourg-Göttingen: Éditions Universitaires- Vandenhoeck 
es un añadido posterior en una sentencia condenatoria más antigua delimitada en Nm 14,11a.23b-24(25) (letra b). Se trata de la intercesión de Moisés ante el Señor, quien ha manifestado su voluntad de terminar con el pueblo y hacer del mismo Moisés un nuevo pueblo elegido (v.12). En efecto, esta resolución divina contrasta con la propuesta en la breve sentencia de Nm 14,11a.23b-24(25). En esta última, todos los israelitas deben perecer mientras que solo Caleb y su clan tomarán posesión de la tierra (cf. Nm 14,24). Con la interpolación de Nm 14,11b-23a, ese desenlace aparece en la forma actual de la sentencia divina como una primera etapa de perdón y esperanza.

ii. Sentencia condenatoria que exime solo a Caleb de la pena capital (Nm $14,11 \mathrm{a} .23 \mathrm{~b}-24[25])$

Este breve discurso contiene la sentencia divina contra el pueblo rebelde en el que se engarza el añadido recién referido. Es fuertemente paralela

\& Ruprecht, 1966), 137.145 y SÉnechal, «Horizon», 612-614. Seguimos a SKa, Introducción, 133-134, que estima que se trata de un añadido redaccional posterior a los pasajes más antiguos de $\mathrm{Nm} \mathrm{13-14}$ por las siguientes razones: a) teología y estilo diferente respecto de aquellos pasajes y otros relatos de permanencia en el desierto. Es evidente su cercanía con Ex 32,7-14 y algunos textos deuteronómicos. En nota el autor pone de manifiesto los principales paralelos con aguda precisión; b)

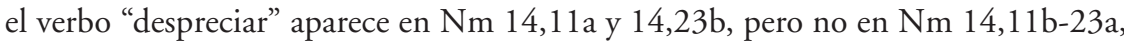
de modo que se puede leer, aunque no con completa fluidez, un continuo sobre el que se añadió un texto "denso" en contenido teológico. Esta misma asignación la sostiene E. Buum, Studien zur Komposition des Pentateuch (Berlin-New York: Walter de Gruyter, 1990), 133-134 (aunque delimita el texto Nm 14,11-25). Cf. también: Ph. J. Budd, Numbers (Wako: Nelson Reference \& Electronic, 1984), 152-153.162 refiere el texto a la literatura deuteronomista; E.W. Davies, Numbers (London: Marshal Pickering, 1995), 142-145 hace lo mismo. SAKenfeld, «Forgiveness», 323-328 considera este texto un suplemento pre-P inserido en el antiguo relato épico de $\mathrm{Nm}$ 14,1b.4.11a.23b-25 (que atribuye a JE), siguiendo los análisis de la Hipótesis Documental Clásica, aunque solo levemente lo conecta con la literatura deuteronomista. Sobre todo, analiza el texto en comparación con Ex 34,6-9. SÉNECHAL, «Horizon», 614-628 estudia las relaciones de dependencia entre Ex 32,7-14; Dt 9,12-14.26-29

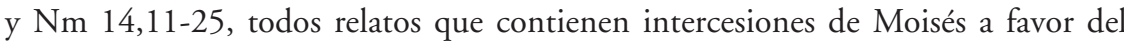

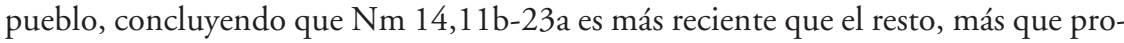
bablemente sea postdeuteronomista y postsacerdotal, inserido en ese lugar precisamente para conectar el pecado del Sinaí/Horeb con el pecado de Cades, como queda

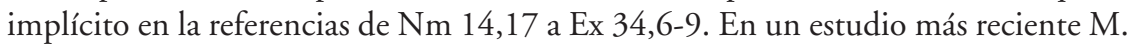
Konkel, Exodus 32-34 and Quest for an Enneateuch (Leiden: Brill, 2012), 183-184 también relaciona $\mathrm{Nm}$ 14:17-20 con Ex 34, 8-9. 
a la sentencia divina reportada en Dt 1,35-36. En efecto, en ambas se exceptúa a Caleb de la pena capital, posibilitándole ver la tierra prometida y entrar en ella, al tiempo que a sus descendientes poseerla como heredad. Además, parece evidente que esta sentencia proviene de la misma mano a la que pertenece sino todo, una buena parte, del material comprendido en Nm 13,28-33, es decir, la segunda parte del reporte de los espías hebreos que entraron en Canaán: la dramática relación que intenta disuadir a los israelitas de que entren a tomar posesión de la tierra prometida a causa de la fuerza y número de sus habitantes ${ }^{11}$.

Se debe notar que el lector atento observa fácilmente la tensión entre el añadido de los vv.11b-23a y el texto donde fue insertado, los vv.11a.23b-24(25). El punto central radica en que implican dos resoluciones divergentes: en el añadido, Moisés y su posteridad tomarán posesión de la tierra prometida; mientras que en la sentencia más antigua, lo harán Caleb y sus descendientes.

iii. Sentencia divina condenatoria que exime a Josué y a los pequeñuelos de la pena capital (Nm 14,26-35)

La sentencia divina de $\mathrm{Nm} \mathrm{14,26-35}$ forma parte con alta probabilidad de una unidad más larga, comprendida en Nm 14,1-10.26-38*. Claro está, no sin reelaboraciones y ajustes menores posteriores, sobre todo para coordinarla con los otros elementos del capítulo. Con mucha probabilidad también está estrechamente vinculada al relato sacerdotal, principalmente por su relación explícita con la narración del censo, relato claramente sacerdotal, y por el uso de vocabulario sacerdotal característico ${ }^{12}$. En efecto, la rebelión ${ }^{13}$ cunde en el pueblo con tintes de desesperación y llanto (cf. Nm 14,1) y luego acaba en crasa murmuración (cf. Nm 14,2-3; cf. Nm 14,27.29.36). En ese angustioso trance, los israelitas se deciden a nombrar un jefe que los lleve de regreso a Egipto, derechamente marcha atrás. Así, la rebelión se vuelve una inversión del

11 En Nm 13,29 se dan referencias concretas de los nombres de los pueblos que habitan la tierra prometida, que se vuelven a citar resumidamente en $\mathrm{Nm} \mathrm{14,25a.}$

12 Para un consideración detenida del estilo y vocabulario, cf. McEvenue, Narrative Style, 103-117, especialmente 103-105.

13 Cf. Ex 17,1-17; Nm 20,1-5; 21,4-6; Dt 9,7.22-24: Sl 78,19-42; 95,8-11; 106,1329 , etc. 
Éxodo (cf. Jr 2,18; Is 30,1-3) ${ }^{14}$. En efecto, los israelitas manifiestan el deseo de volver a la servidumbre en Egipto. Prefieren ser siervos del faraón a vivir en la libertad de siervos del Señor ${ }^{15}$. Recurren a medios humanos -la elección de un caudillo- ante las vicisitudes, desechando la confianza en el Señor. Se muestran incrédulos, pese a que Josué y Caleb insisten en la bondad de la tierra que el Señor les quiere dar y de que sus habitantes son "pan comido" (Nm 14,6-9). Ante esta situación, el Señor sentencia a aquella generación a morir a causa de su murmuración en $\mathrm{Nm}$ 14,26-35. Se salvarán los pequeñuelos: los menores de edad (Nm 14,29), quienes serán introducidos en la tierra prometida y la poseerán ( $\mathrm{Nm}$ 14,31), precisamente aquellos respecto de quienes se argüía que serían tomados en cautiverio por los habitantes del país ( $\mathrm{Nm} \mathrm{14,3} \mathrm{cf.} \mathrm{v.}$ 31). Además de ellos, Caleb y Josué ${ }^{16}$ serán los únicos adultos eximidos de la pena capital decretada ( $\mathrm{Nm} \mathrm{14,30).} \mathrm{Esta} \mathrm{consideración} \mathrm{encuentra}$ confirmación en la narración de la ejecución de la sentencia en $\mathrm{Nm}$ 14,36-38, pues nuevamente en el v. $38^{17}$ se afirma que Josué y Caleb sobrevivieron a la masacre.

En la forma actual del capítulo 14, esta sentencia aparece como una suerte de rectificación y/o ampliación de lo dicho en el v.24, sin que explícitamente se manifieste. Con todo, el lector atento puede notar que aumentan las tensiones que provoca la lectura sincrónica del relato de Nm 13-14: Por una parte, Caleb no es el único exceptuado de la pena capital, sino también Josué. Por otra, no solo la posteridad de Moisés $(\mathrm{Nm} 14,12)$ o la de Caleb (Nm 14,24) estarían en el plan del Señor para ser merecedoras de la heredad prometida, sino también los pequeñuelos,

14 Cf. G.J. Wenham, Numbers. An Introduction \& Commentary (Leicester: Inter-Varsity, 1981), 120-121. Cf. SAKenfeld, "Forgiveness», 321; Levine, Numbers, 377 habla de un "anti-Éxodo"; cf. también S. Boorer, "The Place of Numbers 13$14^{*}$ and Numbers 20:2-12* in the Priestly Narrative (Pg)", JBL 131 n. ${ }^{\circ} 1$ (2012): 56-57.

15 Siguiendo la reflexión de G. Auzou, De la servitude au service. Étude du livre de l'Exode, 3a. ed. (Paris: Éditions de l'Orante, 1968). Wenham, Numbers, 123 subraya que se trata de un rasgo irónico del relato, pues a través de la punición, al menos en parte, Dios da curso al propósito de los rebeldes de no entrar en la tierra que desprecian temiendo la fuerza de sus moradores.

16 Llama la atención que en los vv.6 y 38 el orden de nominación sea Josué y Caleb, mientras que el inverso en el v.30.

17 Es interesante reparar que en este versículo se los nombra de orden inverso que como se hace en el v. 30. 
los menores de edad, de todas las tribus ( $\mathrm{Nm} \mathrm{14,31).} \mathrm{Como} \mathrm{se} \mathrm{dice} \mathrm{más}$ arriba, no pueden sino surgir preguntas irresolubles desde la sincronía: ¿Es que el Señor tiene tres planes diferentes? ¿O rectifica su plan original, ampliando el alcance del perdón?

En consecuencia, una consideración diacrónica resuelve adecuadamente las tensiones. Cabe preguntarse, sin embargo, ¿por qué no se reescribió toda la historia y se las evitó?, ¿por qué se prefirió solo hacer añadidos y reelaboraciones menores que saltan a la vista de cualquier observador? La respuesta excede el propósito de esta reflexión, pero grosso modo se debe afirmar que el Israel postexílico, por una parte, no tiene los medios materiales suficientes para hacerlo ${ }^{18} \mathrm{y}$, por otra, en la literatura israelita rige la "ley de la conservación"19, es decir, que no se pierde nada o casi nada de las distintas tradiciones que confluyen en la comunidad postexílica, integrando en un solo relato compuesto todas esas tradiciones.

\section{Hilos teológicos en las tres VOCES DEL PERdÓN Divino}

La detección de tradiciones escritas fundidas en Nm 13-14 induce a constatar en este pasaje la confluencia de aproximaciones teológicas diversas, las cuales pueden diferenciarse también desde el punto de vista diacrónico:

a) Teología no sacerdotal contenida en la sentencia de Nm 14,11a.23b-24 (25):

Esta sentencia sanciona la cancelación del plan divino, por el cual las doce tribus de Israel debían tomar posesión de la tierra prometida. La condena consiste en la declaración perentoria de que solo Caleb entrará a la tierra y sus descendientes la poseerán. Resulta significativa, pues Caleb se relaciona con la tribu de Judá en la forma actual del relato ${ }^{20}$. De

18 Cf. SKA, Introducción, 237-242 trata la "ley de la economía” de la literatura israelita antigua: con referencias históricas precisas muestra los altos costos y las dificultades de la escribanía del Israel antiguo, con interesantes parangones con la misma función social en otras culturas del Medio Oriente Antiguo y Grecia.

19 Cf. Ska, Introducción, 231-233.

20 No pocos autores señalan que Nm 13-14 tiene a su base una tradición calebita, que sería un relato antiquísimo de la conquista de la región de Hebrón. Se conectaría con otros relatos relacionados con Caleb, de los cuales hay vestigios en otros lugares 
hecho, figura como el espía de esa tribu enviado junto a los otros de los once restantes clanes $(\mathrm{Nm} \mathrm{13,6).} \mathrm{La} \mathrm{falta} \mathrm{de} \mathrm{los} \mathrm{israelitas} \mathrm{es} \mathrm{descrita} \mathrm{con}$ el verbo desdeñar ( $n^{2} S$ s) usado en $\mathrm{Nm} 14,11$ a y $23 \mathrm{~b}$ ), es decir, el desprecio del Señor y de su poder para hacer frente a los robustos habitantes del país y para asaltar sus fortificaciones (cf. Nm 13,28-31).

b) Teología deuteronomista en la condena divina e intercesión de Moisés en $\mathrm{Nm} 14,11 \mathrm{~b}-23 \mathrm{a}$

A la breve sentencia mencionada en el punto anterior, se integra la intercesión de Moisés con que obtiene el perdón divino ante la decisión del Señor de herir al pueblo y desheredarlo, pretendiendo hacer con Moisés un nuevo comienzo de la historia de salvación $(\mathrm{Nm} \mathrm{14,12).} \mathrm{La} \mathrm{decisión}$ divina es una sentencia casi idéntica a la pronunciada por el Señor contra los israelitas a causa de la crisis del becerro de oro (cf. Ex 32,7-10). La razón de fondo radica en que el Señor constata la gran desconfianza del pueblo, que significa en concreto un desdén hacia el mismo Señor. La causa de la sanción, en definitiva, es la falta de fe del pueblo, la cual se relaciona directamente con su incapacidad de entender los signos hechos por Dios a favor de Israel tanto en Sinaí, como en el desierto. En efecto, en Ex 32,9 se habla de un pueblo de "dura cerviz". Esta actitud comporta "la no escucha de la voz del Señor" (cf. Nm 14,22b), esto es, la desobediencia, que naturalmente implica una ruptura de la alianza establecida con Yhwh ${ }^{21}$. Estas dos actitudes, en realidad, constituyen una crasa estupidez, que se agrava por el paso del tiempo. Dios ha mul-

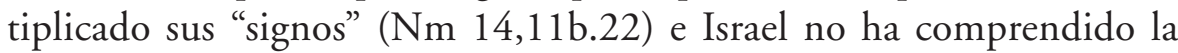
bondad de la obediencia.

Todo hace pensar de que se trata de una teología de marcado cuño deuteronomista: tanto el vocabulario, como el contenido es semejante al del Deuteronomio. Entre otros rasgos ${ }^{22}$, Dios ha hecho "signos" a favor

bíblicos (cf. Nm 32,12; Jos 14,6). Esta tradición habría sido reelaborada e incorporada al sistema de las 12 tribus, haciendo de Caleb el espía de la tribu de Judá ( Nm 13,6). Cf. Budd, Numbers, 143-144, con referencias bibliográficas.

21 Sakenfeld, «Forgiveness», 330 concluye que el suplemento pre-P (vv.11b-23a), supone una alianza condicionada, bilateral. En efecto, para textos no P del Pentateuco, sobre todo de cuño deuteronomista, la alianza es preferentemente condicionada, por ejemplo, Dt 4,39-40; 30,15-20. Cf. Konkel, Exodus 32-34, 183-184.

22 Se reportarán a continuación los principales elementos señalados por SKA, Introducción, 134, n.40. 
de Israel que le deben dar seguridad en que continuará favoreciéndolo (Nm 14,11.22 y Dt 4,34; 6,22-23; 7,19, etc.); el Señor quiere hacer de Moisés un gran pueblo (Nm 14,12b; Ex 32,10; Dt 9,14); el motivo de la "fama del Señor" en la intercesión (Nm 14,13-16; Ex 32,12 y Dt 9,28); la descripción de Dios misericordioso (Nm 14,18; Ex 20,6; 34,7; Dt 5,$10 ; 7,9-10)$ y el delito mismo, no escuchar la voz (Nm 14,22 b y Dt 4,30;8,20;9,23, etc.).

En efecto, la intercesión de Moisés es casi como un remedo de su súplica a favor de los culpables después del incidente del becerro de oro (cf. Ex 32,10-14). Los argumentos esgrimidos son prácticamente los mismos: "el qué dirán los otros pueblos", es decir, la "fama del Señor" (Nm 14,13-16; cf. Ex 32,11-14) y la revelación de la misericordia infinita del Señor (Nm 14,17-19; cf. Ex 34,6-9)23. En este último argumento, además, Moisés explícitamente alude a la automanifestación divina en el Sinaí (cf. v.17). La súplica de Moisés templa la ira destructiva inicial del Señor $(\mathrm{Nm} 14,12)$, quien anuncia la muerte de todos los que vieron la gloria de Dios y las señales que él realizó en Egipto y en el desierto (Nm 14,22; cf. Ex 32,35).

c) Teología sacerdotal en la segunda sentencia del Señor en Nm 14,26-35

La segunda sentencia del Señor es parte del material Nm 14,1-10.26$38^{* 24}$. Se trata de la condena divina que tiene como origen la saturación del Señor ante las quejas que los israelitas le hacen. Ya no resiste más la

23 Olson, Numbers, 83-84 nota, eso sí, que hay una progresión de uno a otro relato: mientras que en Ex 32,12 se refiere a la reputación del Señor entre los egipcios;

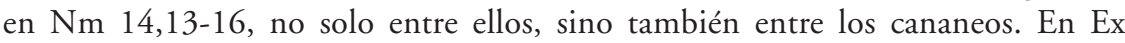
32,13 alude a las promesas hechas a los ancestros del Génesis; en Nm 14,18, a las recientes promesas del Señor hechas a Moisés que encontramos en Ex 34,69. Estas observaciones son congruentes con el hecho evidente que $\mathrm{Nm} \mathrm{14,17-19}$ remite directamente a la sentencia con la cual el Señor resuelve la crisis del becerro de oro. T.R. Ashley, The book of Numbers (Grand Rapids: William Eedermans Publishing Company, 1993), 255 destaca también que en los vv.13-19 se repiten los argumentos de Ex 32,11-14: la reputación del Señor entre las naciones si destruye a su pueblo (vv.13-16) y su mostración como un Dios misericordioso (vv.17-19). Cf. A.R. Petterson, «The Flying Scroll That Will Not Acquit the Guilty: Exodus 34,7 in Zechariah 5,3", JSOT 38 n. 2 (2014).

24 Para un análisis detallado de la atribución a P de gran parte de esta sección, sobre todo desde el punto de vista del estilo, cf. McEvenue, Narative Style, 112-117. También cf. SAKenfeld, «Forgiveness», 328-330 y Boorer, «Place», 54-58. 
murmuración del pueblo y decide que morirán todos los que habían sido censados ${ }^{25}$. Éste dato pone a la luz que se trata de un relato perteneciente a la corriente teológica sacerdotal, uno de cuyos rasgos característicos es la tendencia hacia la "exacta identificación de las personas y los lugares" ${ }^{26}$. Este rasgo se observa profusamente en $\mathrm{Nm} \mathrm{1-4}$ donde se describe el censo de la generación del Sinaí, sobre todo en las largas y nutridas listas en las que se contabilizan todos los que están llamados a ser depositarios de la bendición divina. Por eso, es la teología que mejor se acomoda al apelativo griego del libro: Números. Esta misma preocupación que se observa en la orden de enviar a un explorador por cada tribu (Nm 13,1-2), pues ello conlleva que todas ellas tengan parte activa

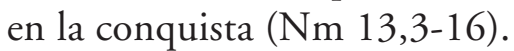

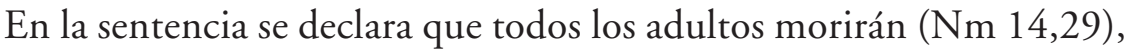
solo restarán Caleb, Josué y los pequeñuelos, esto es, los que en ese momento no tenían uso de razón suficiente como para ser responsables de sus actos. Ellos podrán ver la tierra que sus mayores han "despreciado" (Nm 14,31). El verbo usado para describir el delito de los israelitas es $\mathrm{m}^{2} \mathrm{~s}$, que designa la acción de rechazo o desprecio ${ }^{27}$. Por esta actitud, el "desprecio" 28 , los adultos de Israel caerán en el desierto ${ }^{29}$. El deprecio

25 En esta parte de la sentencia se percibe con claridad que el perdón concedido por el Señor consiste en la preservación del pueblo por una decisión libre de Dios. Esto supone una concepción de la alianza más bien de corte bilateral y condicionada. Sin embargo, SAKEnfEld, «Forgiveness», 330 señala que esta concepción de la alianza pertenece al nivel pre-P, en el cual estaría incorporada la intercesión mosaica (vv.11b-23a). Señala, precisamente que en este contexto el perdón divino se entiende como la preservación del pueblo que Dios hace, no aplicando las disposiciones del pacto bilateral (cf. Nm 14,12). En definitiva en base a su automanifestación que le es recordada por Moisés (cf. Nm 14,17-19 referido a Ex 34,6-7).

26 McEvenue, Narative Style, 91, remitiéndose a los ejemplos contenidos en $\mathrm{H}$. Holzinger, Einleitung in den Hexateuch (Freiburg: J.C.B. Mohr, 1893), 350-352.

27 Diccionario bíblico Hebreo-Español, 1.a ed., s. v. «m”s».

28 En la sentencia antigua antecedente, Nm 14,11a.23b-24(25), en cambio el verbo con que se designa la falta de los israelitas es n’ṣ, "desdeñar" en el v.11a y en el v.23b. Ambos verbos son distintos, aunque con sentidos fuertemente sinonímicos. Cf. Diccionario bíblico Hebreo-Español, 1.a ed., s. v. «n’ș».

29 Wenham, Numbers, 120 señala que en las antiguas leyes de Oriente los que emitían falsas acusaciones recibían la pena que hubieran recibido injustamente los acusados (cf. Dt 19,16-19). Ashley, Numbers, 230-231 destaca que el castigo proviene de la boca de los punidos ("out of their own mouths"), algo así como el popular adagio en español: "por donde pecas, pagas"). 
de los exploradores ha consistido en una "calumnia" contra la tierra prometida (dibba $\bar{a}^{\mathrm{h}}$ 'al-hă $\bar{a}^{\prime}$ reș en Nm 14,36-37; cf. 13,32-33: dibbat hāāareș), con la cual han inducido al pueblo a murmurar contra el Señor (Nm 14,2-3). Por eso, los primeros en morir serán los espías ( $\mathrm{Nm}$ 14,3637). Si bien la falta de los israelitas es algo diferente en esta segunda sentencia en relación a la anterior, apunta a lo mismo, pues el desprecio de la tierra implica el desdén hacia el Señor ${ }^{30}$.

Nos enfrentamos a la teología de los relatos sacerdotales, que se capta bien si se la observa desde un paradigma que incluya los principales relatos atribuidos a la escuela, en una suerte de estructura de los mismos ${ }^{31}$. Esta se basa en unos textos programáticos fundamentales: Gn 1,1-2,4a (creación); 9,1-17 (alianza postdiluviana); 17 (alianza con Abrahán) y Ex 6,2-8 (historia de Israel). En estos programas se plantea una historia en dos partes: la historia de la humanidad y la historia de Israel; cada una subdividida, a su vez, en dos fases. La historia de Israel se subdivide en la historia de los antepasados (los patriarcas) y la historia del pueblo. La articulación entre estas dos fases es remarcada por Ex 2,23b-25 y 6,2-8, pues en ellos se recuerdan las promesas hechas por Dios a los patriarcas (Ex 2,24 y 6,5). De hecho, Dios había prometido tres cosas a Abraham:

- Una gran descendencia (Gn 17,2-6) que se cumple en Gn 47,27 y Ex 2,7.

- Ser su Dios (17,7-8), es decir, la soberanía del Señor sobre su pueblo que se realiza cuando Él pasa a habitar en medio de su pueblo (Ex $25,8 ; 29,45-46$ y sobre todo $40,34-35)$.

- Una tierra $(17,8)$.

Con todo, esta última promesa queda incumplida en el Pentateuco. Los relatos sacerdotales aclaran el porqué: se debe a un fallo del pueblo, del cual es responsable. "La generación del éxodo no ha querido conquistar la tierra según el plan del Señor y por ello ha sido condenada a morir en el desierto. La segunda generación entrará en la tierra prometida a los patriarcas (Nm 14,26-38)"32.

En síntesis, en Nm 13-14 han sido coordinadas al menos tres voces teológicas, de distinto origen, que forman un coro bastante armónico

\footnotetext{
30 VAro, Números, 118 puntualiza que la rebelión "es sobre todo un rechazo de Dios".

31 Seguimos muy de cerca la reflexión de Ska, Introducción, 209-216.

32 Íbid., 213; cf. Olson, Numbers, 86-87.
} 
que con matices canta narrativamente que la posesión de la tierra prometida no será realizada por la generación del Sinaí a causa de su infidelidad y desconfianza para con el Señor.

\section{JUSTICIA Y MISERICORDIA: CRITERIOS FUNDAMENTALES DE LA SENTEN- CIA DIVINA}

A la luz de lo dicho, se colige que la sentencia divina estudiada está sustentada en la justicia. En efecto, el castigo está asociado a la falta de confianza del pueblo en el Señor, precisamente porque esta carencia atenta contra la esencia misma de la alianza ${ }^{33}$. En el Decálogo se manifiesta el estatuto primordial del pacto que sellarán el Señor y los israelitas, toda vez que el Señor lo pronuncia directamente delante de ellos (Ex 20,1-17; cf. Dt 5,6-22, especialmente el último versículo). En algunas de sus disposiciones encontramos los dos principios que hacen patente que la confianza es el núcleo de la fidelidad exigida por la alianza: a) en Ex 20,2 el Señor declara "Yo soy el Señor, tu Dios, que te hice salir de Egipto, de un lugar en esclavitud”. Se trata del sustrato de la alianza: Él es justo y por su propia iniciativa ha actuado en favor del oprimido (cf. Ex 2,23b-25; 3,6-9), aunque no solo para restablecer la justicia, por ejemplo, devolver a los israelitas el estatuto de huésped (cf. Gn 46) que el nuevo faraón le había conculcado (cf. Ex 1-5), sino también para hacerlos su propiedad personal (cf. Ex 19,3-5). Por esta razón, Israel no puede tener otros dioses delante del Señor (es el primer mandamiento: Ex 20,3), ni siquiera ídolos ante los cuales prosternarse (Ex 20,4-5a); b) El Señor es celoso y, por lo mismo, amante, justo y misericordioso a la vez. Así reza Ex 20,5b-6 ${ }^{34}$ :

...porque yo soy el Señor, tu Dios, un Dios celoso, que castigo la culpa (‘āwōn) de los padres en los hijos, hasta la tercera y cuarta generación, si ellos me aborrecen; y tengo misericordia (hesed) a lo largo de mil generaciones, si me aman y cumplen mis mandamientos.

Sin embargo, desde una aproximación superficial, la punición del Señor pareciera ser un acto de justicia que no se condice exactamente con su bondad original. Es más, ante la posibilidad de la muerte como

33 Cf. Boorer, «Place», 56-57.

34 La comparación entre Ex 20,5-6; 34,7-6 y Nm 14,17-19, resulta muy diáfana en Sakenfeld, «Forgiveness», 319.323-328; también en Olson, Numbers, 82-84; Ashley, Numbers, 258-259; Levine, Numbers, 379-381. 
condena divina para el trasgresor, pareciera incluso razonable sostener que lo mejor para el condenado habría sido seguir siendo esclavo en Egipto. Entonces, en cierta medida, las murmuraciones de los israelitas podrían tener al menos algo de razón (cf. Nm 14,2-3).

Ciertamente, la muerte como sanción para los rebeldes es entendida por la sentencia de Nm 14,11-35 (y en el resto del Libro de los Números y del Pentateuco) como desaparición de la existencia, y no como punición medicinal en vista a una vida mejor en el más allá. En efecto, en el Pentateuco una vida postmortem no se encuentra por ninguna parte explícitamente afirmada, sino solo incoada, por ejemplo, en las maldiciones y bendiciones que comportan el cumplimiento y el incumplimiento de la alianza, respectivamente (cf. Dt 30,15-20; Lv 26,3-41). De hecho, la muerte es la maldición suprema. Pero, al mismo tiempo, Dios no se muestra injusto, ni tampoco despiadado. Las intercesión de Moisés en Nm 14,11b-23a, en especial en los vv.17-19 (así como en su intercesiones de Ex 32-33 y también las de Abrahán en Gn 19) indica que el corazón del Señor es misericordioso, "tardo a la ira y lleno de amor", que no paga como merecen los culpables, pero al mismo tiempo que es justo y, por eso, no deja impune el pecado y la trasgresión ${ }^{35}$. En una palabra, que la justicia y la misericordia son dos facetas inseparables en el Señor.

Vale la pena notar que en $\mathrm{Nm}$ 14,17-19 se utilizan dos de los términos bíblicos más relevantes para designar la infidelidad de los israelitas ${ }^{36}$ : ‘ āwōn, es decir, culpa o situación de iniquidad y $\bar{p}$ ešac ${ }^{c}$, esto es, delito o acto de rebelión ${ }^{37}$. En cuanto a la gracia, usa dos expresiones

35 Se trata de una especie de fórmula o confesión de fe que está en las tres partes de la Biblia Hebrea. Se repite, aunque con algunas variaciones y no siempre con todos los términos aludidos. Cf., por ejemplo, en la Ley: Ex 20,6; 34.6-7; Nm 14,18; Dt 4,31; 5,10; 7,9-10; en los Profetas: Jr 32,18; Jl 2,13; Jon 4,2 y Na 1,3; y en los otros escritos: Sl 86,15; 103,8; 116,5; 145,8-9; Ne 9,17b.31.

36 En este párrafo se retoma con alguna modificación los argumentos tratados en A. Ferrada, "Nota de interpretación: YHWH, el Señor, Dios de Misericordia”, en S. Fernández, J. Noemi y R. Polanco, eds., Multifariam, Suplementos a Teología y Vida (Santiago: Anales de la Facultad de Teología 1, 2010), 86.

37 En Ex 34,7 se incluye, además de los dos términos mencionados, hățăa ăh otra designación bastante común de pecado o ruptura e infidelidad a la alianza. En Ex 20,5b-6 solo se usa 'āwōn. Para la revisión de la terminología del pecado en el Antiguo Testamento, cf. A. MeIs, Antropología Teológica. Acercamiento a la paradoja del hombre, 3.a ed. (Ediciones Universidad Católica de Chile: Santiago, 2013), 136-137. 
características del vocabulario que indica el favor divino en el Antiguo Testamento: 'erek 'appayim: es decir, lento a la cólera, o sea, paciente y rab-hesed ${ }^{38}$, esto es, lleno de amor, o sea, amor gratuito, generoso, bondadoso (cf. Jl 2,13; Jon 4,2; Ne 9,17) ${ }^{39}$.

Incluso aún más relevante resulta considerar que en esta parte de su intercesión, Moisés le recuerda al Señor su automanifestación, cuando él accedió a perdonar al pueblo de su infidelidad a la alianza, aún trascurridos solo 40 días de su establecimiento, aseverando de sí mismo en Ex 34,6a-7:

El Señor es un Dios compasivo y bondadoso, lento para enojarse ('erek 'appayim), y lleno en amor (rab-hesede y fidelidad. Él mantiene su amor (hesed ) a lo largo de mil generaciones y perdona la culpa (‘̄āwōn), la rebeldía $\left(\overline{\mathrm{p}} \mathrm{eša}^{c}\right)$ y el pecado; sin embargo, no los deja impunes, sino que castiga la culpa ('āwōn) de los padres en los hijos y en los nietos, hasta la tercera y cuarta generación.

Esta autorevelación en cierta medida completa la manifestación de su enigmático nombre: "seré el que seré" (Ex 3,14). En efecto, pone de manifiesto que el Señor existe en favor de Israel, incluso cuando este no merece sino la destrucción y el abandono. Israel comprende que ello se debe solo a la grandeza del amor del Señor (kî ləcôlām ḥasdô, "porque eterno es su amor", Sl 136,1ss; cf. Sl 117,2).

En Nm 14,17-18 se encuentra condensado este mismo mensaje en labios de Moisés. Ahora ante la murmuración de los israelitas desencadenada por los informes de los espías, que degenera en un intento de regresar a Egipto, el caudillo de Israel intercede nuevamente a fa-

38 SAKENFELD, «Forgiveness», 324 señala que esta expresión se usa restrictivamente solo referida a Yhwh.

39 En Ex 34,6-7 se incluyen otros más: rahûm de rahămîm, entrañas maternas y, por lo mismo, connota un amor entrañable, tierno, como el de una madre por su hijo (cf. Os 2,21); hannûn de hẹen, es decir, clemente, en relación con la actitud del poderoso que se inclina sobre el pequeño y, por lo tanto, denota clemencia y benignidad (cf. Ex 33,12-17; Sl 86,15; 103,8); 'ěmet (a la raíz de amén), es decir, fiel, designando la fidelidad del Señor consigo mismo, con sus promesas y, por tanto, cierto y seguro (cf. Jos 2,14; 2Sam 2,6). Hasta cierto punto esta multiplicidad se puede atribuir al carácter concreto de la mentalidad judía, de modo que cada uno de los términos usados designa un aspecto de la bondad divina. Para una revisión de los términos que indican gracia divina en el Antiguo Testamento, cf. Meis, Antropología Teológica, 134-136. Se ha retomado con alguna modificación Ferrada, "YHWH, el Señor", 89. 
vor del pueblo rebelde apelando a la memoria del Señor de su misma automanifestación:

Por eso, Señor, manifiesta la grandeza de tu poder, como tú lo has declarado, cuando dijiste: «El Señor es lento para enojarse ('erek 'appayim) y está lleno

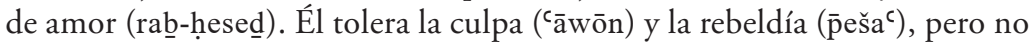
las deja impunes, sino que castiga la culpa ('āwōn) de los padres en los hijos y en los nietos hasta la cuarta generación».

La formulación es menos florida en vocabulario que su antecedente (Ex 34,6-7), pero no menos expresiva, ya que Moisés pide al Señor que perdone la culpa del pueblo, precisamente en atención a su "gran amor": kəōōdel hasdek $\bar{a}$, "porque grande es tu amor" (Nm 14,19).

\section{ConClusión}

La sentencia divina de $\mathrm{Nm}$ 14,11-35, si bien se sustenta en la justicia del Señor, pues, de hecho, recalca que solo los culpables serán ajusticiados, mientras que los inocentes se verán incólumes; no se la puede comprender sino desde el horizonte de la misericordia divina que es aun más grande que su justicia. En efecto, en Nm 14,18 (y en Ex 34,7) es manifiesto que el Señor no deja impune las culpas; al contrario, estas son castigadas aunque en una proporción ínfima en relación al perdón y a la misericordia: el Señor castiga hasta la tercera o cuarta generación en relación a las mil generaciones por las que mantiene su amor y fidelidad (Ex 34,7). Si bien en Nm 14,18 está ausente la referencia a las "mil generaciones" ${ }^{\prime 40}$, debe suponérsela pues se trata de una alusión explícita del discurso de Ex 34,7. La desproporción significa que el Señor mantiene su amor y perdona la culpa eternamente, mientras que su punición es solo temporal. Esta disparidad se deja ver también en la petición de perdón que de inmediato Moisés formula al Señor en Nm 14,19: la razón fundamental para que el Él perdone, es decir, decrete justicia, es precisamente la grandeza de su amor.

La desproporción pone ante una profunda revelación de la identidad divina: Yhwh, el Señor, Dios de misericordia.

40 No pocas traducciones del pasaje vierten lẳălāp̄îm en "por millares", el sentido literal de la palabra; otras interpretan la palabra en relación a la paradoja que expresa el contexto: "por mil generaciones" en contraste con "tercera y cuarta generación". Por eso, la expresión también puede verterse en el adverbio "eternamente". 
Pareciera que en Nm 14 se obviara la conciencia de la responsabilidad personal, o al menos fuera proclive a una cierta imputación de culpas ajenas a los inocentes, las de los padres a los hijos, nietos y hasta los bisnietos. Se debe afirmar que la responsabilidad personal no está desarrollada en estos versículos. Sin embargo, en las dos versiones de la sentencia divina, las dos voces que se describen coordinadas, a saber, en Nm 14,22-24 (probablemente texto deuteronomista) y Nm 14,29-32 (probablemente texto sacerdotal) no se decreta la punición de los hijos por el pecado de los padres, sino que se acentúa que los castigados son responsables de sus actos; incluso Dios les ha tolerado ya diez veces sus

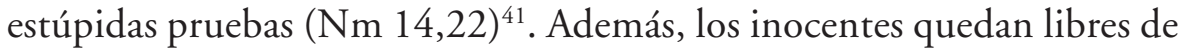
todo castigo: Josué, Caleb y los privados de uso de razón. En conclusión, la punición de los padres en los hijos en Nm 14,18-19 (y también en Ex $20,5-6 ; 34,7-8)$ es una expresión simbólica que enfatiza la desproporción entre la misericordia y la justicia del corazón de Dios. En efecto, esta desproporción es el horizonte de sentido principal, en el cual se debe interpretar el castigo que comporta la peregrinación de Israel por el desierto. 